\title{
O BORDADO COMO FERRAMENTA EDUCACIONAL NO BRASIL ENTRE OS SÉCULOS XIX E XX
}

\author{
Carolina Nascimento Pereira* \\ Gláucia Maria Costa Trinchão*
}

\section{RESUMO}

Este artigo discorre sobre a presença do desenho como ferramenta doutrinadora, de técnicas rígidas e temas angelicais, na formação educacional das meninas através do ensino do bordado no final do século XIX e início do XX. Assim, é analisado como bordar foi um saber transposto do espaço doméstico para a vivência escolar, consolidando a concepção deste trabalho manual como uma atividade exclusivamente feminina e destacando a integração entre o desenhar e o bordar ao longo de sua prática em sala de aula. A compreensão deste tema é costurada pela análise acerca do cenário político e social da época, através do desenvolvimento da educação formal e os ideais de feminilidade vigentes entre o Brasil colonial, imperial e republicano. A partir deste estudo, identificam-se aspectos que influenciam no século XXI a continuidade da criação de bordaduras no cenário brasileiro.

Palavras-chave: bordado, desenho, educação, mulher, Brasil.

\footnotetext{
${ }^{*}$ Universidade Estadual de Feira de Santana (UEFS), Novo Horizonte/BA, Brasil.

${ }^{* *}$ Universidade Estadual de Feira de Santana (UEFS), Novo Horizonte/BA, Brasil.
} 


\section{EL BORDADO COMO HERRAMIENTA EDUCATIVA EN BRASIL ENTRE LOS SIGLOS XIX Y XX}

\section{RESUMEN}

Este artículo analiza la presencia del dibujo como herramienta adoctrinadora, de técnicas rígidas y temas angelicales, en la educación de las niñas a través de la enseñanza del bordado a finales del siglo XIX y principios del XX. Así, se analiza cómo el bordado fue un conocimiento transpuesto del espacio doméstico a la experiencia escolar consolidando la concepción de esta obra manual como una actividad exclusivamente femenina y destacando la integración entre dibujo y bordado a lo largo de su práctica en el aula. La comprensión de este tema está cosida por el análisis sobre el escenario político y social de la época a través del desarrollo de la educación formal y los ideales de feminidad prevalecientes entre el Brasil colonial, imperial y el republicano. A partir de este estudio, identificamos aspectos que influyen en el siglo XXI en la continuidad de la creación de bordado en el escenario brasileño.

Palabras clave: bordado, dibujo, educación, mujer, Brasil.

\section{EMBROIDERY AS AN EDUCATIONAL TOOL IN BRAZIL BETWEEN $19^{\text {TH }}$ AND $20^{\text {TH }}$ CENTURY}

\section{ABSTRACT}

This article discusses about the presence of drawing as an indoctrinate tool, of rigid technic and angelical themes, in formal education for girls through the teaching of embroidering during the final years of the $19^{\text {th }}$ and early $20^{\text {th }}$ Century. Thereby, it is analysed how embroidery was a knowledge transposed from domestic field to academic experience consolidating this manual work as an exclusively feminine activity and highlighting the integration between drawing and embroider throughout their classroom practice. The comprehension of this theme is sewn by the analyses of the political and social scenario of the time through the development of formal education and the prevailing of femininity ideals between colonial, imperial and republican Brazil. Based on this study, it is identified aspects that have influenced the continuity of the creation of embroidery in the $21^{\text {st }}$ Century.

Keywords: embroidery, drawing, education, women, Brazil.

\section{LA BRODERIE COMME OUTIL ÉDUCATIF AU BRÉSIL ENTRE LE XIXE ET LE XXE SIÈCLE}

\section{RÉSUMÉ}

Cet article traite de la présence du dessin comme outil d'endoctrinement, de techniques rigides et de thèmes angéliques, dans l'éducation des filles à travers l'enseignement de la broderie à la fin du XIXe siècle et au début du XXe siècle. Ainsi, il est analysé comment la broderie a été une connaissance transposée de l'espace domestique à l'expérience scolaire consolidant la conception de ce travail manuel comme une activité exclusivement féminine et soulignant l'intégration entre 
le dessin et la broderie le long de son pratique en classe. La compréhension de ce thème est cousue par l'analyse sur le scénario politique et social de l'époque à travers le développement de l'éducation formelle et les idéaux de féminité qui prévalent entre le Brésil colonial, impérial et républicain. A partir de cette étude, nous identifions les aspects qui influencent au XXIe siècle la continuité de la création de broderie dans le scénario brésilien.

Mots-clés: broderie, dessin, education, femme, Brésil. 


\section{INTRODUÇÃO}

Bordar e desenhar são atividades práticas que se inter-relacionam. O bordado é uma técnica que configura a criação de imagens a partir da manipulação da agulha e da linha em tecido, criando ou produzindo desenhos temáticos pré-traçados ou desenhos criativos livres, que se constituem em Desenho Bordado. Logo, bordado é técnica, é prática e é produto, assim como o desenho.

Bordaduras, crochê, tricô, renda, entre outros, são exemplos de práticas têxteis que constituem o grupo dos trabalhos de agulha que criam desenhos através da manipulação das fibras. $\mathrm{O}$ ato de bordar, tão vasto em suas características e finalidades, é uma prática presente na cultura material brasileira que se mantém viva nas diversas realidades de diferentes regiões do país, a exemplo do bordado filé, Richelieu, ponto cruz, redendê, vagonite, entre tantos outros tipos, sempre produzindo sobre tecido desenhos em variados padrões.

Além de seu aspecto técnico, o bordado possui uma trajetória histórica que se entrelaça com as histórias das mulheres e os lugares por elas ocupados nos grupos sociais. No Brasil, entre os séculos XIX e XX, o bordado passou a ser ensinado nas escolas direcionadas exclusivamente para as classes frequentadas por meninas, onde aprendiam a técnica através da criação de mostruários compostos por desenhos estilizados com temáticas florais, além dos abecedários com tipografias sofisticadas. Elas ainda aprendiam o ponto cruz, entre outros pontos tradicionais, para desenvolverem o conhecimento de desenhar com agulha e linha.

Sendo assim, este artigo discorre sobre o período histórico em que o ato de bordar atravessa o espaço doméstico e é incluído como uma ferramenta doutrinadora para os primeiros grupos de garotas brasileiras a frequentarem $o$ espaço escolar formal. Ao colocar o desenho bordado como objeto central de pesquisa na virada entre o Brasil Imperial e o Brasil Republicano, é possível compreender as especificidades que consagraram o bordado como um trabalho 
realizado por mulheres, as características da sociedade brasileira pelo viés das questões de gênero, destacar a presença do conhecimento em desenho na formação feminina, conhecer as raízes do desenvolvimento da educação formal no Brasil oitocentista e indagar como as concepções sobre o ato de bordar ainda permeiam essa prática no século XXI.

\section{BORDAR: UMA EXPRESSÃO CONTEMPORÂNEA}

Tecido, linha e agulha: esses três elementos são suficientes para realizar um bordado, uma forma de criar desenhos que possui a sua raiz na intenção de ornamentar tecidos. Apesar da acessibilidade dos materiais, bordar constitui um trabalho manual com uma história milenar que engloba uma pluralidade visual expressa em diversas modalidades e com finalidades múltiplas. Ao transitar pelo Brasil nas primeiras décadas do século XXI, encontramos uma produção têxtil a partir desta técnica em diferentes regiões, fazendo do bordado uma presença abrangente em nossa cultura material.

A história de como esta prática se desenvolveu em solo brasileiro não possui um número vasto de registros, e há poucas pesquisas dedicadas a investigar o seu percurso histórico. Porém, ao seguirmos as pegadas das diferentes etnias que constituem a formação do país, identificamos uma herança dos imigrantes europeus que amalgamamos aos trabalhos manuais previamente existentes dos povos indígenas. No que concerne aos trabalhos decorativos com agulha, vemos que, a partir do século XVI, "os ingleses, espanhóis e portugueses disseminaram técnicas europeias pelo mundo através do processo de exploração e conquista" (LESLIE, 2007, p. 12, tradução nossa). De acordo com Silva (1995), o bordado trazido pelos portugueses para o Brasil apresentava padrões provenientes de países como Espanha, França, Bélgica, além de Portugal. A manipulação de fibras têxteis já era uma prática explorada pelos habitantes nativos no Brasil pré-colonial, que utilizavam fios de algodão, entre outras fibras de origem vegetal, para confeccionar vestimentas e variados tipos de acessórios e 
artefatos (ABREU; BENINI, 2016).

O bordado permanece no século XXI desenrolando o seu caminho pelas mãos de mulheres e homens que veem neste labor artesanal a possibilidade de conexão com um conhecimento ancião. Segundo publicado pelo jornal Estado de Minas, em dezembro de 2016, pelas jornalistas Marta Vieira e Marinella de Castro, bordar é um ofício presente em 76\% dos municípios brasileiros, de acordo com dados obtidos pelo IBGE em 2014. Só no estado de Sergipe, 96\% dos seus 75 (setenta e cinco) municípios exercem esta prática, seguido de Minas Gerais e Goiás no número de bordadeiras e bordadores atuantes.

Olhar para a criação de bordaduras em diferentes épocas, assim como na contemporaneidade, traz possibilidades de compreender aspectos sociais, políticos e artísticos. Em entrevista à Revista Continente (2017), no artigo Bordado, arte contemporânea, a artista visual pernambucana Clara Nogueira descreve o trabalho têxtil como: "Uma ferramenta muito potente". Nogueira faz parte de uma geração de brasileiros e brasileiras que utilizam agulha e linha como elemento de suas poéticas artísticas. Através do texto do jornalista Eduardo Montenegro, somos também apresentados à realidade das bordadeiras da cidade de Passira, cidade do interior de Pernambuco, que possui o bordado como um meio de sobrevivência e resiste há décadas aos altos e baixos de seu ofício. Através dessa realidade dicotômica entre o artístico e artesanal, Nogueira questiona: "Por que o que eu faço é considerado arte e o que elas fazem não?" - "elas" são as bordadeiras de Passira (MONTENEGRO, 2017).

Em outra reportagem, desta vez no Jornal O Globo (2018), a jornalista Carolina Callegari traz um breve apanhado da exposição realizada no Museu Arthur Bispo do Rosário, no Rio de Janeiro, do Coletivo Almofadinhas, composto por três artistas: Rodrigo Mogiz, Fábio Carvalho e Rick Rodrigues. A reportagem evidencia a discussão sobre masculino e feminino que a produção do Coletivo suscita e conclui já em seu título que a exposição "mostra que bordado é coisa de homem”.

Tais referências textuais no contexto do século XXI apontam o quanto a 
prática do bordado ainda pulsa nas múltiplas realidades brasileiras. $\mathrm{Na}$ contemporaneidade, $\mathrm{o}$ ato de bordar se coloca a serviço de composições visuais que trazem desenhos com temáticas diversificadas atuantes em diferentes conjunturas. Observar este fazer traz um imbricado de informações sobre quem borda e o que borda, fazendo emergir e questionar a enraizada relação do bordado como um fazer feminino, e as implicações atreladas a essa concepção.

Apesar dos dados supracitados confirmarem sua vasta presença em nossa cultura, a prática de bordar ainda é alvo de desvalorização econômica e cultural. É verdade que o bordado feito manualmente tem despertado o interesse de gerações mais novas, que buscam aprender os pontos tradicionais - basta investigar o número de canais e vídeos nas plataformas on-line dedicadas a este fazer. A quantidade de profissionais ministrando oficinas de bordado e incentivando a realização desta prática também é um fenômeno de nossa época.

Ainda assim, pouco conhecemos sobre a história dos bordados domésticos e seu percurso histórico em solo brasileiro, já que eram realizados por mulheres anônimas na intimidade de suas casas em outras décadas e séculos. Nos espaços museológicos, não nos deparamos com este tipo de produção, em parte pelo pouco interesse em investigá-los e pelos poucos exemplares que sobreviveram à ação do tempo ou dos herdeiros. "Também negligenciados pelos livros de história, de história da arte e mesmo design ou cultura material, os artefatos têxteis domésticos são praticamente ilustres desconhecidos dos estudos científicos" (MALTA, 2015, p. 2).

Parker (1996) expressou no prefácio de sua publicação que "conhecer a história do bordado é conhecer a história das mulheres” (n. p., tradução nossa). Bordar, uma prática que se configura também como um saber, foi entre os séculos XIX e XX utilizado como ferramenta doutrinadora para as meninas que ingressavam à educação formal nas escolas do Brasil. Ainda no tempo vigente e no cenário brasileiro, é quase inevitável pensar que bordar é um trabalho feito por mulheres e consumido por mulheres. Encontra-se consolidada em nosso imaginário esta premissa, construída em paralelo ao percurso feminino na 
sociedade.

Na busca do entendimento de como tal associação foi naturalizada, e de como a organização educacional e social da época ainda ecoa em nossa forma de encarar esta prática é necessário recorrer a uma análise que perpassa por variados campos de conhecimento para a compreensão acerca dos papéis relegados à mulher durante o período investigado. A partir deste estudo, também podemos identificar de quais formas os aspectos ideológicos e culturais sobre a prática de bordar, enraizados nos séculos anteriores, continuam a atuar sobre as nossas percepções e vivências com as bordaduras.

\section{BORDADO E O IDEAL DE FEMINILIDADE DO SÉCULO XIX}

Sabemos que as divergências das atuações sociais de homens e mulheres não se deram a partir de um determinismo biológico, como foi defendido em alguns momentos históricos, e sim, por uma construção cultural. Sendo assim, Rosaldo (1979) ressalta que, através da pesquisa biológica, obtemos informações sobre os aspectos físicos e humanos, mas estes dados não devem servir para explicar fatores culturais. Portanto, a biologia:

pode contar-nos sobre a proporção das dotações dos grupos ou de indivíduos particulares, mas não pode explicar o fato de que em todos os lugares as culturas têm determinado o Homem como uma categoria oposta à Mulher em valor social e importância moral (ROSALDO, 1979, p. 39).

As diferenças biológicas entre homens e mulheres são inegavelmente existentes; mas, enquanto foram utilizadas como justificativa para engessar os papéis cabíveis a ambos os sexos, aprofundou-se o caminho para a subordinação da mulher à esfera doméstica ou a trabalhos em condições precárias e socialmente desvalorizados. Dentro dessa lógica, Albernaz e Longhi (2009, p. 78) 
elucidam que "todos os indivíduos eram iguais, mas para serem iguais em direitos, políticos e sociais, os indivíduos não poderiam ser diferentes”. Uma exigência humanamente impossível, pois "para ser igual era preciso ser idêntico! Dessa maneira a desigualdade entre os sexos viria das diferenças biológicas, assim como a desigualdade entre raças.”

A leitura realizada sobre os corpos humanos a partir das diferentes funções fisiológicas e características físicas entre os indivíduos serviu como argumento para a estruturação social que separa os campos de atuação de homens e mulheres. A condição feminina encarada como mais próxima da natureza, por estar atrelada à ação de gestar e parir, restringiu o exercício político da mulher ao ambiente do lar, à família ou a ofícios em que a mão de obra feminina não fosse valorizada e, frequentemente, necessitava de autorização do pai ou cônjuge para ser exercida. O poder de criação feminino estava na gestação dos filhos, no trabalho de alimentá-los e zelar pelo desenvolvimento deles na infância. E essa ocupação colabora na restrição da sua atuação na sociedade por intermédio do espaço doméstico. "Em outras palavras, o corpo feminino parece condená-la a mera reprodução de vida” (ORTNER, 1979, p. 104).

É preciso reconhecer que, dentro dessa dicotomia estabelecida entre homens e mulheres e feminino e masculino, havia ainda subdivisões a partir da classe social. Assim, a separação de campo de atuação pelos sexos entre público e privado nem sempre era, na prática, absolutamente separado. As mulheres da burguesia eram, segundo Monteiro e Gati (2012, p. 3072), "solicitadas a praticar a caridade e a filantropia." Já as mulheres das camadas economicamente menos favorecidas trabalhavam em diferentes ofícios, "como costureira, fiandeira, fabricante de botões ou de rendas, ourives, polidora de metais, cervejaria, criada de lavoura, criada doméstica ou ama, mas sem visibilidade."

Os estudos nos campos da anatomia e da biologia foram explorados no intuito de explicar cientificamente o que era, na verdade, o subterfúgio encontrado para justificar a crueldade das dinâmicas sociais. A dita inferioridade de determinados grupos étnicos e das mulheres encontrava respaldo em 
pesquisas científicas de estudiosos que pareciam não reconhecer o papel do sistema político e social na segregação dos seres humanos e que se refletiam em todas as esferas de atuação e convívio. No livro Maria Bonita: sexo, violência e mulheres no cangaço (2018), a autora Adriana Negreiros discorre sobre como no Brasil do início do século XX certas características físicas eram apresentadas por médicos e cientistas como determinantes à expressão de tendências criminosas, corroborando com ideias do psiquiatra italiano Cesare Lombroso, que defendia que "alguns homens, por não terem evoluído por completo, constituíam-se criminosos natos" (NEGREIROS, 2018, p. 56). Por esse motivo, os corpos dos cangaceiros e, em especial, suas cabeças, eram visados como objetos de estudo, colocando em prática a frenologia, em que se buscava identificar a delinquência nas características físicas do cérebro.

"Os fisiologistas do final do século XIX, que pesquisam as localizações cerebrais, afirmam que as mulheres têm um cérebro menor, mais leve, menos denso" (PERROT, 2007, p. 97). Tal afirmação é apenas um entre os fatores anatômicos utilizados no período histórico aqui investigado para explicar o porquê de as mulheres não possuírem capacidade criativa. Essa visão contribuiu para a desvalorização da prática do bordado como uma expressão cultural e artística. O lugar intelectualmente inferiorizado das mulheres era uma manobra constante na defesa de que qualquer produção feminina não era detentora de valor intelectual ou cultural. Estando o bordado categorizado como uma produção feminina, era natural que este fosse encarado como uma ferramenta doutrinadora, um passatempo, mas não com a qualidade de um produtor de conhecimento.

Os conceitos idealizados de feminilidade e masculinidade também contribuíram para a implantação dessa estrutura separatista que impregnava as produções materiais. Embora ambos tenham se modificado entre a passagem da Idade Média para a Idade Moderna (OLIVEIRA, 2004), muitas especificidades sobre o que é feminino e masculino foram sedimentadas nos anos 1800, permanecendo expressivas na vivência dos anos posteriores através de uma 
disseminação do estereótipo definido de características típicas de mulheres e homens.

$\mathrm{Na}$ encenação da vida coletiva, competia ao homem oitocentista interpretar o papel oposto ao da mulher, ou seja, expressar força, altivez, coragem e racionalidade. Concluímos, então, que "ser homem no século XIX significava não ser mulher, e sobre todas as hipóteses jamais ser homossexual" (SILVA, 2000, p. 11). Segundo Oliveira (2004, p. 71): "Enquanto o masculino simbolizava a ordem e o progresso, o feminino deveria expressar a castidade, a pureza, o comedimento público e outras características que não confrontavam a submissão da mulher às figuras masculinas, pais e maridos, sobretudo".

O lugar do feminino era visto como oposto ao masculino e, consequentemente, homens e mulheres eram encarados como seres absolutamente distintos e isolados em suas condições unicamente masculina ou feminina, jamais uma integração dos dois. No que concerne especificamente ao modelo de feminilidade, é preciso lembrar que essa é uma "identidade vivida por mulheres seja aceita ou resistida" (PARKER, 1996, p. 04, tradução nossa). E o ideal de feminilidade está em constante movimento, modificando-se de uma época para a outra. Além disso, Parker (1996) destaca que as características que atribuímos ao estereótipo de feminino frequentemente não reconhece os diferentes tipos de mulheres, suas pluralidades culturais, de classe e, até mesmo, geográficas. Este não olhar para a heterogeneidade das mulheres é também tratado por Chadwick (1996, p. 176, tradução nossa) quando conclui que "o ideal de feminilidade da classe-média estigmatizou muitos grupos de mulheres como depravadas - aquelas que permaneceram sem casar, que trabalhavam, ou eram escravas, ou imigrantes, ou socialmente radicais".

A dinâmica social analisada aponta os discursos disseminados e que comandaram a segregação pautada por gênero e classe. Essas ideias ajudaram a moldar não apenas a convivência das relações no âmbito público, mas, também, na esfera privada. Essa organização aponta para o quanto o conjunto desses fatos "reforçava esse cenário familiar característico: das leis civis aos preceitos 
religiosos, passando pelas narrativas e romances populares, que apoiavam os estereótipos de gênero" (OLIVEIRA, 2004, p. 49). No que concerne à interação entre o bordado e as mulheres, percebe-se que o conceito de feminilidade:

através de atividades como bordado e desenho contribuiu diretamente para a consolidação de uma identidade burguesa na qual as mulheres possuíam o momento de lazer para cultivar "realizações" artísticas (CHADWICK, 1996, p. 148, tradução nossa).

Certas atividades eram naturalizadas como sendo apropriadas para mãos femininas. A costura e todos os trabalhos manuais que envolviam agulha e linha se encaixavam nesta modalidade. A estrutura social que impregnou a ato de bordar encontrou um aliado a partir do desenvolvimento do sistema formal de educação, principalmente entre o século XIX e as primeiras décadas do XX. O bordado foi frequentemente usado como uma das ferramentas ou saberes ensinados ao corpo discente feminino, fazendo parte das disciplinas e das prendas domésticas essenciais à formação das alunas que deveriam ser preparadas para as suas funções como esposa e dona de casa, uma concepção moldada por muitos anos e finalmente consagrada no século XIX. A repercussão da relação estabelecida entre programa educacional, mulheres e bordado sedimentou boa parte dos conceitos que permanecemos identificando no século XXI relacionados à prática de bordar.

\section{A MULHER NA EDUCAÇÃO FORMAL BRASILEIRA}

A inserção de meninas na educação formal foi um processo longo que obedeceu a particularidades em cada país. Dentro da sociedade ocidental, e em especial na Europa, as mulheres iniciaram o seu percurso em ambientes educacionais obedecendo às mudanças sociais, econômicas e políticas a partir do século XVII. Aprender a ler e escrever foi uma necessidade criada principalmente pelas religiões cristãs, que passaram a defender a importância de que seus fiéis 
lessem a Bíblia e aprofundassem os seus conhecimentos religiosos contra as possíveis heresias (MONTEIRO; GATI, 2012).

Não por acaso, os espaços religiosos foram os primeiros a possibilitar às mulheres que usufruíssem de um ambiente que proporcionasse a vivência educacional fora do ambiente doméstico. Os conventos não apenas abrigavam aquelas que escolhiam a dedicação exclusiva à religião, mas também abrigava meninas e mulheres socialmente desamparadas, ou seja, que não possuíam marido ou família. Segundo Stamatto (2002), junto aos espaços religiosos, às mulheres era permitido praticar a leitura, a escrita, noções básicas de matemática e estudos da doutrina cristã, além, claro, das atividades têxteis.

No Brasil, a organização educacional com a qual somos familiarizados levou séculos para se consolidar. Nos anos de colonialismo português, a alfabetização era limitada a uma parcela mínima e masculina da população mais abastada, sendo este público doutrinado por professores particulares e pelos jesuítas que aqui chegaram em 1549, vindos da Europa. A Companhia de Jesus foi responsável durante dois séculos pela educação em terras brasileiras. Sua criação no auge da contrarreforma possuía dois principais objetivos: "a educação dos homens e dos indígenas; e a ação missionária, por meio das quais procuraram converter à fé católica os povos das regiões que estavam sendo colonizadas" (MACIEL; NETO, 2006, p. 468).

O acesso à educação voltada para os homens no Brasil foi uma normalidade nos primeiros anos de colonização, uma vez que socialmente a mulher era concebida "para o casamento, ou para a vida religiosa, ou para o trabalho doméstico e escravo, práticas que precisavam de pouca ou nenhuma educação escolar" (STAMATTO, 2002, p. 3). É importante ressaltar que, além da restrição pautada em questões de gênero, o Brasil colonial era uma grande terra ainda pouco conhecida pelos europeus que buscavam colocar em prática a exploração dos recursos naturais para o enriquecimento da coroa portuguesa. Portanto, criar um sistema educacional democrático e efetivo não se configurou entre as prioridades mais imediatas (KRAUSE; KRAUSE, 2016). 
Com a expulsão da Companhia de Jesus, duzentos anos após a sua chegada, por Sebastião José de Carvalho, o Marquês de Pombal, os jesuítas perderam a função de mentores da educação; e com a Reforma Pombalina, "o ensino passa a ser responsabilidade da Coroa Portuguesa" (MACIEL; NETO, 2006, p. 469). Tal ruptura, forçou um redirecionamento no desenvolvimento do sistema educacional que, na época, foi fortemente influenciado pelas ideias iluministas. A reforma que começa a ser implantada em meados do século XVIII não significou, na prática, um apagamento total do estilo jesuítico de educação (MACIEL; NETO, 2006). Porém, trouxe alguns novos elementos ao sistema educacional das escolas primárias do então Brasil colonial, em destaque a permissão cedida às meninas para frequentarem a sala de aula com o alvará concedido em 1758. Segundo Stamatto (2002), esse alvará não significou uma frequência expressiva da população feminina nas escolas, mas a pesquisadora relata alguns exemplos pontuais em diferentes regiões do território brasileiro.

As décadas subsequentes às reformas pombalinas não proporcionaram um desenvolvimento homogêneo do sistema educacional no país. As escolas públicas do Brasil adentraram o século XIX ainda com instalações precárias, muitas eram mantidas por congregações religiosas ou por cidadãos leigos. Esta escassez e deficiência desprovia a sociedade brasileira que contava ainda com uma população majoritariamente analfabeta. Até meados do século XVIII, o Brasil era um país rural existindo sob a estrutura de uma sociedade escravocrata e pouco afetuosa às ideias democráticas. Estabelecer um cenário com acesso igualitário à educação não condizia, portanto, com os aspectos políticos e culturais da época. Sobre essa realidade, Vasconcelos (2007, p. 26) pontua que:

Aos obstáculos culturais, políticos e sociais relacionados à sociedade escravista e desigual se somavam a falta de orçamento nas províncias para um investimento que demandava amplos recursos para a concretização da universalização da instrução e que, ainda, teria que acarretar profundas mudanças nos hábitos na população. 
Ao longo das décadas dos anos oitocentistas, as transformações políticas com a chegada da família real portuguesa em 1808 e a independência alcançada em 1822 trouxeram a necessidade de organizar institucionalmente o país. Simultaneamente, o governo é pressionado a reestruturar as poucas escolas espalhadas em território nacional. A defesa de que o país precisava se industrializar e se aproximar do ideal civilizatório de outros países resvala também na defesa de que para modernizar a sociedade era imperioso um programa educacional disponível inclusive para as mulheres.

Sendo assim, algumas reformas, tanto no funcionamento das escolas, quanto na formação dos professores, começaram a delinear a existência dos espaços de ensino. As mulheres no Brasil do século XIX, que ainda enfrentavam restrições à vivência escolar, dão mais um passo em direção ao acesso à educação com a promulgação da Lei Geral do Ensino, de 15 de outubro de 1827, na qual se buscava determinar um padrão de funcionamento do ambiente escolar em todo o país. No Art. $11^{\circ}$ da lei em questão, é explicitado que: "Haverão escolas de meninas nas cidades e villas mais populosas, em que os Presidentes em Conselho julgarem necessário este estabelecimento" (BRASIL, 1827). E no Art. $12^{\circ}$ fica claro sobre quais seriam os conhecimentos a serem ensinados:

\begin{abstract}
Art $12^{\circ}$ As mestras, além do declarado no art $6^{\circ}$, com exclusão das noções de geometria e limitando a instrucção da arithmetica só as suas quatro operações, ensinarão tambem as prendas que servem á economia domestica; e serão nomeadas pelos Presidentes em Conselho, aquellas mulheres, que sendo brazileiras e de reconhecida honestidade, se mostrarem com mais conhecimentos nos exames feitos na fórma do art. $7^{\circ}$ (BRASIL, 1827).
\end{abstract}

A profissão de docente era, até então, ocupada por homens. Quando as meninas começaram a frequentar o ambiente escolar em turmas, a princípio separadas dos meninos, surge a demanda da contratação de mulheres para ocuparem o cargo de magistério. Os motivos para o ingresso da mão de obra feminina em uma profissão previamente masculina são variados, porém, a causa 
principal recaiu nos "impedimentos morais dos professores educarem as meninas e a recusa à coeducação dos sexos, liderada pelo catolicismo conservador" (ALMEIDA, 1998, p. 94).

O processo de feminilização da profissão docente aconteceu de forma acelerada em vários países, entre meados do século XIX até as primeiras décadas do século XX. Neste período histórico, o discurso de que as mulheres eram naturalmente aptas no trato com as crianças era constante, "portanto nada mais adequado do que lhes confiar a educação escolar dos pequenos" (MONTEIRO; GATI, 2012, p. 3091). Mais uma vez, é perceptível a influência dos estereótipos masculinos e femininos, previamente delineados neste artigo, na presença de mulheres na sala de aula. Para o público feminino, as aulas deveriam ser ministradas exclusivamente por professoras. Às candidatas a este emprego era necessário atenderem ao requisito de serem detentoras de uma moral exemplar. Assim:

\footnotetext{
a professora deveria ter uma certa idade, solicitar autorização do pai ou do marido se fosse casada, apresentar a certidão de óbito se viúva, e, se separada, justificar sua separação comprovando comportamento honrado (STAMATTO, 2002, p. 06).
}

As professoras deveriam direcionar a aprendizagem em prol de saberes considerados úteis para a formação daquelas que seriam responsáveis pela ordem e prosperidade do lar. Ainda que a inclusão cada vez maior de meninas nas escolas formais pudesse apontar um dado positivo na discussão de equidade de gênero na época, essa presença não significava um acesso igualitário de conhecimento. E, acerca do corpo docente e do respectivo conteúdo a ser ensinado, era determinada uma divisão. A escolarização de meninas deveria "ter um currículo diferente daquele dos meninos, já que não se pretendia favorecer a sua inserção no mundo do trabalho" (MONTEIRO; GATI, 2012, p. 3072).

Segundo Louro (2004), a vivência de meninos e meninas no espaço escolar brasileiro possuía em comum a aprendizagem da leitura e escrita, as 
quatro operações básicas da matemática e os estudos da doutrina cristã para ambos os sexos, "mas logo algumas distinções apareciam: para os meninos, noções de geometria; para as meninas, bordado e costura" (LOURO, 2004, p. 444).

Antes que o tema sobre o uso da técnica do bordado como ferramenta educacional avance, é necessário destacar sobre qual parcela da população estamos nos referindo quando são mencionados os meninos e meninas que frequentavam a escola no Brasil recém independente. A população rural tinha pouco acesso às escassas unidades escolares existentes; os indígenas, ainda que portassem o próprio sistema educacional proveniente dos seus costumes e organização cultural, "sua presença, era, contudo, vedada nas escolas públicas" (LOURO, 2004, p. 445). A segregação sofrida pela população negra ao longo de séculos, imersa nas mazelas do regime escravocrata, certamente os excluiu da participação de qualquer acesso à educação formal da época. E sobre esta circunstância é ressaltado que:

Para a população de origem africana, a escravidão significava uma
negação de qualquer forma de escolarização. A educação das crianças
negras se dava na violência do trabalho e nas formas de luta pela
sobrevivência. As sucessivas leis, que foram lentamente afrouxando os
laços do escravismo, não trouxeram, como consequência direta ou
imediata, oportunidades de ensino para os negros. São registradas
como de caráter filantrópico as iniciativas que propunham a aceitação
de crianças negras em escolas ou classes isoladas - o que vai ocorrer no
final do século (LOURO, 2004, p. 445).

A partir dos dados históricos aqui apresentados, é possível reconhecer o cenário no qual é constituída a época sob análise. Através do entendimento dos elementos políticos e sociais que compõem o entorno do desenvolvimento da educação formal no Brasil, torna-se mais fácil compreender como o bordado e outras técnicas trabalhadas através da manipulação da agulha e da linha são selecionados como ferramentas indispensáveis para a formação prática e intelectual da mulher. 


\section{O BORDADO: DE CASA PARA A ESCOLA ATRAVÉS DA DISCIPLINA DE TRABALHOS MANUAIS}

O bordado tornou-se um saber essencial na formação das garotas do Brasil oitocentista, juntamente com outras práticas que possuíam uma aura feminina, e, portanto, passíveis de serem ensinadas. A presença desta prática como uma ferramenta doutrinadora nas escolas não era uma exclusividade brasileira. Instituições de Ensino em diferentes países lançavam mão das aulas concentradas no bordado em seus espaços educacionais. Na cidade de Cartago, na Colômbia, a aprendizagem do bordado pelas mulheres de classes privilegiadas teve início no século XIX nos colégios religiosos e "vai progressivamente inserindo-se no interior do lar, transmitindo-se de uma geração de mulheres a outra” (PÉREZ-BUSTOS; GUTIÉRREZ, 2015, p. 289, tradução nossa). Parker (1996) traz o exemplo da escola para garotas em Lamberth, Londres, onde, em 1713, seu currículo era composto de "leitura, escrita, tecelagem, tricô, costura e marcações (mostruários de letras)" (PARKER, 1996, p. 107, tradução nossa). Ou seja, o ensino dos bordados manuais às meninas que frequentavam a escola não foi uma novidade do século XIX, e foi empregado em diferentes nações a partir de circunstâncias e objetivos similares.

Mas, como pontuam Louro e Meyer (1993), o que vemos no ambiente da educação formal não é uma mera tradução de um saber doméstico para um saber escolar. "O que haverá será um processo que nós denominamos de escolarização do doméstico” (LOURO; MEYER, 1993, p. 50). Essa transposição de atividades e saberes para o programa das disciplinas escolares, há muito, forma uma discussão sobre como os modos de vida e os aspectos culturais de uma sociedade são selecionados para, então, configurar-se como um conhecimento a ser ensinado e perpetuado através da vivência escolar. Não aprofundaremos aqui os pormenores de como a escola em cada tempo realiza essa seleção, pois esse assunto é abissal e possui elementos suficientes para a escrita de um outro artigo. Evidenciamos, porém, o quanto essa seleção não se dá de forma homogênea e obedece, de acordo com Forquin (1993, p. 35), ao que ele chama de "metáfora da 
bricolagem", em que o conhecimento empírico é reelaborado para preencher uma demanda momentânea de reforçar um conhecimento em particular.

A associação estabelecida entre as mulheres e a produção de bordados começou a se consolidar nos séculos anteriores ao período em questão neste artigo. De acordo com Parker (1996), na Europa, até o século XVIII ainda era comum encontrar homens e mulheres compartilhando o ofício de bordadores. $\mathrm{O}$ bordado era encarado como uma expressão com dimensões artísticas e ainda não era estereotipado como uma prática doméstica ou como fonte de renda para a classe trabalhadora, ainda conforme a autora. Antes do século XIX, os bordadores "continuaram a compartilhar as mesmas preocupações estilísticas e iconográficas dos pintores, escultores e trabalhadores de metal" (PARKER, 1996, p. 71). Ainda assim, a partir do século XVI, a naturalização de que bordar era um trabalho feminino e doméstico começa a ser delineada.

O período renascentista deu início a uma nova relação entre as práticas classificadas como artísticas, e o trabalho do artista e do artesão, previamente mantidos em um mesmo patamar, começam a se distanciar, criando uma hierarquização e incorporando uma escala de valores. Para Simioni (2007), o artista, a partir da renascença, passou a ser visto como um indivíduo autônomo, com conhecimento técnico e intelectual, que possuía o respaldo da vivência das academias de arte com acesso às aulas de modelo vivo, ambiente do qual as mulheres eram banidas e "cujo conhecimento era central para as pinturas de história e para os retratos, gêneros que ocupavam o cume da hierarquia acadêmica" (SIMIONI, 2007, p. 94). Os trabalhos têxteis, como a tapeçaria e o próprio bordado, até então logrados como nobres, iniciam um percurso de desvalorização e consequente domesticação, ao serem atrelados, juntamente com a aquarela, pinturas decorativas e retratos, a atividades artísticas de mulheres (SIMIONI, 2007).

Por mais que as mulheres tivessem acesso à aprendizagem de diferentes técnicas, desde o desenho à escultura, havia uma forte delimitação sobre a temática desta produção. Chadwick (1996) deixa claro o quanto era socialmente 
aceitável que uma mulher, ao se dedicar ao fazer artístico, apenas retratasse paisagens bucólicas, naturezas mortas, retratos e elementos florais. Ainda que haja na história da arte registros de mulheres artistas que fugiram desse padrão, como a pintora italiana Artemisia Gentileschi, elas configuravam uma exceção e estavam sujeitas a toda espécie de descrédito pelos seus trabalhos. Essa vigilância sobre o tema das obras recai sobre o bordado, que majoritariamente era produzido a partir de desenhos padronizados de elementos da natureza ou religiosos.

O que apreendemos no desenrolar dos séculos XVI e XVIII na sociedade europeia e que se consagra no século XIX, simultaneamente no Brasil, é o lugar cada vez mais subserviente da mulher, ainda que, a depender da classe social à qual ela pertencesse, trouxesse especificidades de como esse lugar inferiorizado e submisso acontecia na experiência cotidiana. De forma geral, o livre acesso ao conhecimento e à educação para as mulheres não era socialmente aceito. E para defender tal ideologia, os mais variados argumentos eram utilizados. "O saber demasiado numa mulher, alertam, representa um perigo, pois pode conduzir a neuroses e ao celibato forçado" (MONTEIRO; GATI, 2012, p. 3079).

No Brasil, a disciplina de Trabalhos Manuais passou a integrar o currículo escolar ainda no período imperial. Já sabemos que, ao longo dos anos 1800, a grade de aulas era bastante distinta entre meninos e meninas. Apesar desta distinção ter sido gradativamente abolida ao longo dos anos, duas disciplinas mantiveram a divisão baseada no gênero até as primeiras décadas do século XX: ginástica e trabalhos manuais (SOUZA, 2017).

Para as filhas da parcela aristocrática da população brasileira, assim como os colégios dedicados à educação de órfãs e meninas de classes média e baixa dos anos em questão, o acesso à rotina escolar trazia um caráter catequizador. Com o reconhecimento de que as mulheres possuíam uma importante influência na formação de seus filhos, o século XIX aponta "para a necessidade de educação da mulher, vinculando-a à modernização da sociedade, à higienização da família, à construção da cidadania dos jovens” (LOURO, 2004, 
p. 447).

Ao longo da pesquisa realizada por Carvalho (2017), que investigou o ensino religioso e as disciplinas de trabalhos manuais também entre os séculos XIX e XX, a pesquisadora ressalta que, no Brasil, todas as escolas existentes, independentemente de serem religiosas ou não, particulares ou públicas, possuíam a disciplina de trabalhos manuais. "Nas leis que regularam a escolaridade feminina durante o Império e República, o ensino de trabalhos de agulha era obrigatório" (CARVALHO, 2017, p. 104-105).

O trabalho têxtil concentrado na costura e no bordado, presentes na esfera doméstica, passa a integrar a grade curricular escolar voltada para a educação de meninas, fortalecendo a já existente ligação entre o sexo feminino e a produção de bordaduras. No entanto, é preciso destacar que tal ligação não possuía finalidades homogêneas. Além da segregação educacional estipulada por gênero, no que concerne à educação feminina, também são perceptíveis diferenciações nos programas das disciplinas de acordo com a classe social das alunas. $\mathrm{O}$ ato de bordar era direcionado a todas as meninas que frequentavam o espaço escolar; porém, a classe social à qual estavam atreladas ditava o propósito da obrigação em saberem produzir um bordado (CARVALHO, 2017).

Havia uma distinção explícita, ao investigarmos como a disciplina de trabalhos manuais era conduzida nas escolas destinadas às alunas de famílias abastadas e as escolas para órfãs ou meninas de classes mais pobres. "Para as escolas destinadas às órfãs e segmentos populares, sua função era prioritariamente a formação de mão de obra competente" (CARVALHO, 2017, p. 112). Portanto, os trabalhos de agulha assumiam o papel de se tornarem um meio de sobrevivência, um trabalho remunerado. Por outro lado, as meninas das classes médias possuíam a costura e o bordado como um fazer doméstico voltado para suprir as utilidades do lar. Já as alunas provenientes das famílias mais ricas desfrutavam das aulas de bordado como um sinal de seu caráter feminino refinado. Para uma mulher de elite, branca, que desfrutava do conforto material provido por um homem, pai ou marido, saber bordar era uma demonstração 
social de sua feminilidade, refinamento, doçura, moral - características idealizadas e cobradas à mulher (CARVALHO, 2017).

Na execução de um bordado, há sempre uma presença primogênita do desenho. Assim como bordar, o desenhar também adentrou o espaço escolar brasileiro no século XIX. Sua trajetória perpassa pelas transformações causadas desde a Revolução Francesa à Revolução Industrial, quando desenhar era encarado também como um saber teórico a serviço das novas funções industriais, derivadas das artes aplicadas e dos trabalhos artesanais. O desenho passa a transitar entre o fazer artístico e a ciência. Porém, a sua inserção na educação formal possuía os objetivos de instrumentalizar os futuros trabalhadores das indústrias artísticas (DÓRIA, 2004), e de corroborar com o discurso de que a população, principalmente a mais pobre, precisava ser educada. Desenhar, então, era visto como uma ferramenta doutrinadora com o poder de desenvolver a sensibilidade e, assim, entra "para os espaços escolares oitocentistas como efeito moralizador social e como capacitadores da sociedade que se queria na época" (TRINCHÃO, 2019a, p. 39).

O contato com a prática do desenho passou a fazer parte do currículo escolar de meninos e meninas nas escolas normais, com finalidades distintas. Ao que concerne à educação feminina, foco deste artigo, desenhar era mais um entre os saberes que compunham o quadro de disciplinas com o intuito de moldar a mulher, esposa e mãe, dentro da premissa da figura da moça prendada. Saber desenhar, bordar, costurar e os cruzamentos possíveis de tais práticas serviam à construção da imagem de requinte e de possível desenvolvimento de mão de obra, pautada na classe social da aluna. No que concerne à etapa prática da aprendizagem, no trato com os materiais, as condições eram as mesmas para todas as alunas. Segundo é descrito por Gaeta (2002, p. 5):

a sala de Trabalhos Manuais estava equipada com os requisitos oficiais: material para costura, bastidores para bordado; panos de amostra, pranchetas e havia um compromisso com os pais das alunas de se manter uma Exposição permanente. 
Os tecidos mais utilizados eram o linho e o algodão, de preferência na cor branca, pela associação da cor à pureza e por ser mais fácil identificar qualquer vestígio de sujeiras e defeitos não tolerados na execução de um bordado. $\mathrm{Na}$ construção dos desenhos a serem bordados, era comum que as meninas usassem o recurso de amostras, modelos reproduzidos e bordados pelas discentes em tecidos anexados a um caderno escolar individual ou em pedaços de pano em forma de quadrado. Os desenhos eram provenientes de imagens padrões com um repertório voltado para elementos com um caráter ornamental, o que aponta pouca liberdade de escolha e criação nos desenhos bordados realizados pelas alunas. Esse recurso se tornou frequente a partir do século XVII como uma forma de acompanhar o desenvolvimento das alunas (CARVALHO, 2017). Os mostruários de pontos traziam variados tipos, desde os pontos de contorno (haste, atrás etc.) aos pontos de entremeios (Richelieu e Ajour) e o famoso ponto cruz. Tais pontos eram selecionados para constituir os desenhos de elementos botânicos, símbolos cristãos ou abecedários. Assim, limitava-se a temática das bordaduras às figuras e desenhos que possuíam uma relação com o ideal de feminilidade e o discurso moral e religioso, elementos que construíam um vocabulário com visual romântico.

No artigo escrito por D’enfert (2007) sobre o ensino do desenho linear nas escolas francesas do século XIX, o autor menciona a inserção do ensino do desenho como uma ferramenta auxiliadora à aprendizagem dos trabalhos de costura. Este tipo de ensino do desenhar possuía o intuito disciplinador de treinar o olhar a partir de uma prática que se concentrava em formas geométricas, sem o rigor do efeito de luz e sombra, e que partia de formas simples como o quadrado e o círculo para preparar os jovens para as profissões nas indústrias. Segundo D’enfert (2007), as aulas de desenho linear nas primeiras décadas do período oitocentista passaram a ser obrigatórias para os meninos com a implantação da Lei Guizot em 1833. Para as meninas, a obrigatoriedade chega em 1836, quando "o desenho linear não é considerado como uma arte recreativa, mas visa sobretudo oferecer às moças modelos de referência em bordado e em confecção" (D'ENFERT, 2007, p. 40). 
Essa mesma associação entre o ensino do desenho e demais técnicas têxteis é evidenciada por Vaquinhas (2000), ao abordar a educação feminina em Portugal no mesmo período. No texto, a autora ressalta o ensino técnico no espaço dos Liceus para garotas da classe trabalhadora, onde, com a presença feminina em atividades têxteis manuais e industriais, buscava-se "através do ensino do desenho, da tecelagem, das rendas, da costura e dos bordados assegurar uma formação profissional” (VAQUINHAS, 2000, p. 99).

Desenhar constitui uma etapa prévia na criação de um bordado. Antes que a linha faça o seu percurso sobre o tecido, é costumeiro traçar o desenho que serve como molde para a imagem que queremos bordar. Este desenho é realizado obedecendo a formas simples, sem a necessidade de detalhamentos. Em seguida, a imagem gráfica é passada para o tecido com o auxílio do papel carbono, através da técnica do decalque. No Brasil, as aulas de desenho foram integradas a partir do século XIX como uma forma de instrumentalizar os jovens, preparando-os para funções profissionais nas indústrias, em especial nos espaços dos Liceus de Artes e Ofícios. O Desenho também constituiu o currículo das escolas como disciplina, em cujo conteúdo pedagógico era comum o desenho de ornamentos (LIMA, 2008).

Os elementos ornamentais são uma constante nas composições visuais bordadas, o que aponta a conveniência de que a aprendizagem de ambas as práticas se relacionem, estando o desenho no lugar de um conhecimento preparatório para o ato de bordar. De acordo com Trinchão (2019b), o ensino do desenho linear foi integrado à realidade brasileira, e a sua implantação também obedecia à mesma finalidade baseada no gênero descrita por D'enfert (2007). Enquanto os meninos aprendiam um desenho voltado para o conhecimento técnico, as meninas se utilizavam dessa aprendizagem para aprimorar a prática dos trabalhos de agulha.

As etapas da produção de bordados, entre o desenhar sobre o tecido e manipular a linha e a agulha, deveriam, conforme Carvalho (2017), obedecer à exigência de limpeza e perfeição. As meninas que não conseguissem realizar um 
bordado a partir de tais premissas eram criticadas pela sua falta de habilidade manual refletindo em uma ausência das características atribuídas ao ideal de feminilidade da época. Em um bordado limpo e perfeito, a mão da bordadeira era imperceptível, o anverso e avesso do tecido eram praticamente o mesmo, e não havia qualquer linha solta ou frouxa. Bordar sobre o desenho preestabelecido constituía uma ação rigorosa com uma rigidez quanto aos detalhes formais na materialização deste desenho. Para alcançar essas exigências, era preciso fazer, desfazer e refazer um mesmo ponto quantas vezes fosse necessário, ajudando a enaltecer, segundo Carvalho (2017, p. 103) o quanto bordar é "cansativo, persistente, árduo, regrado, pouco reconhecido, mas que confere à sua praticante o zelo, a docilidade e a humildade de quem cuida e se dedica com amor ao que é seu."

Para Pérez-Bustos e Gutiérrez (2015, p. 291, tradução nossa), a aprendizagem do bordado era voltada também "a disciplinar o corpo e controlar a mente." Uma visão corroborada por Carvalho (2017, p. 55), ao ressaltar o quanto as prendas domésticas e a manipulação dos elementos têxteis "colaboraram para o desenvolvimento de condutas corporais específicas da feminilidade". Bordar era uma ferramenta que auxiliava a mulher a ocupar o tempo ocioso, a se dedicar à decoração e ordenação do espaço doméstico, além de expressar o seu recato, cuidado, silêncio e submissão.

O lugar ocupado pelo bordado e pela costura na educação feminina foi, ao longo do século XX, perdendo esse espaço fundamental. Até meados do século passado, ainda era possível encontrar escolas no Brasil que ensinassem os trabalhos de agulha como um saber integrado aos assuntos de economia doméstica. $\mathrm{O}$ abandono do ensino dessa prática na sala de aula foi atravessado por mudanças no lugar ocupado pelas mulheres na sociedade e pela seleção de outros conhecimentos tidos como essenciais, de acordo com a dinâmica de um outro tempo.

O que constatamos, ao realizar uma análise do programa educacional destinado às meninas entre o século XIX e parte do XX, foi o quanto este período 
traz informações de como certas concepções sobre o que é bordado começaram a ser construídas em momentos prévios e sedimentadas no tempo investigado. Através do ensino do bordado e do seu percurso histórico em constante relação com as condições das mulheres na sociedade, demonstra-se o quanto a produção têxtil e os trabalhos de agulha estão embebidos de discursos e podem ser manipulados para reforçar ideias e modos. Realizar um estudo sobre a sociedade a partir do bordado evidencia o quanto os trabalhos de agulha "colaboram para os estudos históricos de gênero, pois eles inserem as mulheres na sociedade, são matrizes de identidade de gênero e mediadores de relações sociais" (CARVALHO, 2017, p. 96).

Fica claro, ao analisar o desenvolvimento do sistema educacional da época, que a inclusão feminina na educação formal, como professoras e alunas, não se configurava objetivamente como uma busca de emancipação para as mulheres ou equivalência de atuação com os homens. Este objetivo foi paulatinamente sendo alcançado na medida que as demandas sociais e as reivindicações dos movimentos feministas criaram ruídos na organização vigente. A educação era tomada por um ponto de vista excessivamente masculino e discriminatório. "Esse olhar buscava conformar as mulheres à obediência e à submissão, como mostra o fato de, até o século XVII, as mulheres serem, em sua grande maioria, analfabetas" (ALMEIDA, 2010, p. 57).

De maneira inevitável, identificamos um possível paralelo entre a época investigada e o tempo em curso no século XXI, no que concerne ao olhar sobre a prática do bordado. Abandonamos a concepção de que bordar é um trabalho delicado, primoroso e, portanto, feminino? Ao compreender como os trabalhos de agulha foram direcionados com finalidades distintas às meninas de diferentes classes no espaço escolar do século XIX, indagamos se essa divisão se manteve no tempo do qual somos contemporâneas, ainda que o cenário atual traga novos elementos e circunstâncias.

Ao debruçar o olhar sobre o bordado na contemporaneidade, é possível identificar o quanto dentro da multiplicidade desta prática ainda encontramos 
resquícios ou absoluta presença de conceitos em voga em tempos passados. Traçar uma relação entre o período temporal aqui pesquisado e a contemporaneidade é o ponto que mantém essa pesquisa ainda sem um ponto final.

\section{CONCLUSÃO}

Investigar a produção material humana nos coloca diante da objetificação de conceitos, ideologias e formas de viver de um determinado grupo em um tempo específico. Ao encarar o bordado como uma produção passível de absorver e revelar as dinâmicas de uma sociedade, confirmamos o quanto a realização desta prática reflete a hierarquia social estratificada a partir da divisão entre classes econômicas, gênero e raça.

Conhecer o cenário histórico que viabilizou a sua transposição de trabalho manual doméstico para conhecimento ensinado nas escolas do Brasil nos séculos XIX e XX possibilitou compreender, além dos seus aspectos formais de produção, a sua consagração como uma atividade feminina e anônima. Muito da sua pluralidade se deve a essa contaminação pela dinâmica da época e que reverbera na forma como encaramos os trabalhos de agulha na contemporaneidade.

Estudar uma criação aparentemente tão singela e íntima, proporciona um conhecimento que aponta a falta de neutralidade dos artefatos que produzimos. E, mesmo quando se trata de uma sociedade que não mais vive entre nós, percebemos a sobreposição de tempos que misturam os conceitos contemporâneos com os de um passado não tão distante.

Ainda que o bordado, nessas primeiras décadas do século XXI, reinventese através de desenhos com temáticas cada vez mais plurais e bordadores de procedências diversas, continuamos a enxergá-lo como um fazer delicado e dominado pelas mãos de mulheres, especialmente as das classes mais pobres. A 
partir da sua análise, simultaneamente entre o presente e o passado, conseguimos talvez compreender o que une e o que separa a produção de uma artista como Clara Nogueira e as bordadeiras de Passira.

\section{REFERÊNCIAS}

ABREU, Ana Cláudia de; BENINI, Ana Maria Leopaci. Etnodesign como ferramenta de resgate da memória brasileira nos artefatos indígenas. Icônica, v. 2, p. 209-235, 2016.

ALBERNAZ, Lady Selma Ferreira; LONGHI, Márcia. Para compreender gênero: uma ponte para relações igualitárias entre homens e mulheres. In: SCOTT, Parry; LEWIS, Liana; QUADROS, Marion Teodósio de (org.). Gênero, diversidade e desigualdades na educação: interpretações e reflexões para formação docente. Recife: Editora Universitária Ufpe, 2009.

ALMEIDA, Flávia Leme de. Mulheres recipientes: recortes poéticos do universo feminino nas artes visuais. São Paulo: Cultura Acadêmica, 2010.

ALMEIDA, Jane Soares de. Mulher e educação: a paixão pelo impossível. São Paulo: Editora Unesp, 1998.

BRASIL. Lei de 15 de outubro de 1827. Manda crear escolas de primeiras letras em todas as cidades, villas e logares mais populosos do imperio. Coleção de leis do império do Brasil - 1827, página 71 vol. 1 pt. i (publicação original). Disponível em: https://www2.camara.leg.br/legin/fed/lei_sn/1824-1899/lei38398-15-outubro-1827-566692-publicacaooriginal-90222-pl.html. Acesso em: 13 jan. 2020.

CALLEGARI, Carolina. Coletivo Almofadinhas, com três artistas, mostra que bordado é coisa de homem. Jornal O Globo Rio. Maio, 2018. Seção Bairros. Disponível em: https://oglobo.globo.com/rio/bairros/coletivo-almofadinhascom-tres-artistas-mostra-que-bordado-coisa-de-homem-22719334. Acesso em: 19 nov. 2019.

CARVALHO, Mariana Diniz de. Educando donzelas: trabalhos manuais e ensino religioso (1859-1934). 2017. 241 f. Dissertação (Mestrado em Ciências História Social) - Faculdade de Filosofia, Letras e Ciências Humanas, Universidade de São Paulo/USP, São Paulo/SP, 2017. 
CHADWICK, Whitney. Women, art and society. 2 ed. London: Thames and Hudson, 1996.

D’ENFERT, Renaud. Uma nova forma de ensino de desenho na França no início do século XIX: o desenho linear. Tradução de Maria Helena Câmara Bastos. História da Educação, Asphe, p. 31-60, mai./ago. 2007.

DÓRIA, Renato Palumbo. Entre a arte e a ciência: o ensino do desenho no Brasil do século XIX. In: MARTINS, Roberto de Andrade; MARTINS, Lilian Al-Chueyr Pereira; SILVA, Cibelle Celestino; FERREIRA, Juliana Mesquista Hidalgo (ed.). Filosofia e história da ciência no Cone Sul: $3^{\circ}$ Encontro. Campinas: AFHIC, 2004.

FORQUIN, Jean Claude. Escola e cultura: as bases sociais e epistemológicas do conhecimento escolar. São Paulo: Editora Artes Médicas, 1993.

GAETA, Maria Aparecida Junqueira Veiga. Entre rendas e bordados: memórias de uma disciplina escolar. In: CONGRESSO NACIONAL DE HISTÓRIA DA EDUCAÇÃO, II, 2002, Natal/RN. História e memória da educação

brasileira. Natal/RN: Universidade Federal do Rio Grande do Norte, 2002, v. 1., p. 220-230.

KRAUSE, Cristina da Silva Cavalcanti; KRAUSE, Maico. A educação de mulheres do período colonial brasileiro até a o início do século XX: do imbecilitus sexus à feminização do magistério. In: SIMPÓSIO LINGUAGENS E IDENTIDADES DA/NA AMAZÔNIA OCIDENTAL, X, 2016, Rio Branco/Acre. Anais... Rio Branco: 2016.

LESLIE, Catherine Amoroso. Needlework through History: an Encyclopedia. 1 ed. London: Greenwood Press, 2007.

LIMA, Solange Ferraz de. O trânsito dos ornatos: modelos ornamentais da Europa para o Brasil, seus usos (e abusos?). An. Mus. Paul., São Paulo, v. 16, n. 1, jan./jun. 2008.

LOURO, Guacira Lopes. Mulheres na sala de aula. In: PRIORE, Mary del (org.). História das mulheres no Brasil. 7 ed. São Paulo: Contexto, 2004.

LOURO, Guacira Lopes; MEYER, Dagmar. A escolarização do doméstico: a construção de uma escola técnica feminina. Cad. Pesq., São Paulo, n. 87, p. 4557, nov. 1993.

MACIEL, Lizete Shizue Bomura; NETO, Alexandre Shigunov. A educação brasileira no período pombalino: uma análise histórica das reformas 
pombalinas do ensino. Educação e Pesquisa, USP, v. 32, p. 465-476, 2006.

MALTA, Marize. Paninhos, agulhas e pespontos: a arte de bordar o esquecimento na história. In: SIMPÓSIO NACIONAL DE HISTÓRIA, XXVIII, 2015, Florianópolis/SC. Anais... Florianópolis: Anpuh, 2015, v. 1, p. 1-12.

MONTEIRO, Ivanilde Alves; GATI, Hajnalka Halasz. A mulher na história da educação brasileira: entraves e avanços de uma época. In: SEMINÁRIO NACIONAL DE ESTUDOS E PESQUISAS "HISTÓRIA, SOCIEDADE E EDUCAÇÃO NO BRASIL”, IX, 2012, João Pessoa/PA. Anais... João Pessoa: Ufpa, 2012, v. 01, p. 01-25.

MONTENEGRO, Eduardo. Bordado, arte contemporânea. Revista Continente, Recife, Seção Reportagem, 24 out. 2017. Disponível em: https://www.revistacontinente.com.br/secoes/reportagem/bordado--artecontemporanea. Acesso em: 14 mar. 2019.

NEGREIROS, Adriana. Maria Bonita: sexo, violência e as mulheres no cangaço. 1 ed. Rio de Janeiro: Objetiva, 2018.

OLIVEIRA, Pedro Paulo. A construção da masculinidade. Belo Horizonte: Editora UFMG, 2004.

ORTNER, Sherry B. Está a mulher para o homem assim como a natureza para a cultura? In: ROSALDO, Michelle Zimbalist; LAMPHERE, Louise (coord.). A mulher, a cultura e a sociedade. Tradução de Cila Ankir e Rachel Gorenstein. Rio de Janeiro: Paz e Terra, 1979.

PARKER, Rozsika. The subversive stitch: embroidery and the making of the feminine. Londres: Edição Revisitada, 1996.

PÉREZ-BUSTOS, Tânia; GUTIÉRREZ, Sara Márquez. Aprendiendo a bordar: reflexiones desde el campo sobre sobre el oficio de bordar y investigar.

Horizontes Antropológicos, Porto Alegre, ano 21, n. 44, p. 279-308, jul./dez. 2015.

PERROT, Michelle. Minha história das mulheres. Tradução de Angela M. S. Côrrea. São Paulo: Contexto, 2007.

ROSALDO, Michelle Zimbalist. A mulher, a cultura e a sociedade: uma revisão teórica. In: ROSALDO, Michelle Zimbalist; LAMPHERE, Louise (coord.). A mulher, a cultura e a sociedade. Tradução de Cila Ankir e Rachel Gorenstein. Rio de Janeiro: Paz e Terra, 1979.

SILVA, Maria Regina M. Batista e. O universo da bordadeira: estudo 
etnográfico do bordado em Passira. 1995. 190 f. Dissertação (Mestrado em Antropologia) - Universidade Federal de Pernambuco/UFPE, Recife, 1995.

SILVA, Sergio Gomes da. Masculinidade na história: a construção cultural da diferença entre os sexos. Psicol. Cienc. Prof., Brasília, v. 20, n. 3, set. 2000.

SIMIONI, Ana Paula Cavalcanti; GRAZ, Regina Gomide: modernismo, arte têxtil e relações de gênero no Brasil. Revista do IEB, n. 45, p. 87-106, set. 2007.

SOUZA, Rosa Fátima de. Espaço da educação e da civilização: origem dos grupos escolares no brasil. In: SAVIANI, Dermeval [et.al]. O legado educacional do século XIX. [livro eletrônico] Campinas, SP: Autores Associados, 2017. Coleção Educação Contemporânea.

STAMATTO, Maria Inês Sucupira. Um olhar na história: a mulher na escola (Brasil: 1549-1910). In: CONGRESSO BRASILEIRO DE HISTÓRIA DA EDUCAÇÃO, II, 2002, Natal/RN. Anais... Natal: SBHE, 2002.

TRINCHÃO, Glaucia Maria Costa. O papel social do desenho na formação do homem novo oitocentista. Educar em Revista, Curitiba, v. 35, n. 73, p. 33-48, jan./fev. 2019a.

TRINCHÃO, Glaucia Maria Costa. História da educação em desenho: institucionalização, didatização e registro do saber em livros didáticos lusobrasileiros. 1 ed. Curitiba: Appris, 2019b.

VAQUINHAS, Irene. Os caminhos da instrução feminina nos séculos XIX e XX. Breve Relance. Turres Veteras III, Actas de História Contemporânea, Câmara Municipal de Torres Vedras, Instituto de Estudos Regionais e Municipalismo Alexandre Herculano, 2000.

VASCONCELOS, Maria Celi Chaves. A educação doméstica no Brasil de oitocentos. Revista Educação em Questão, UFRN, v. 28, p. 24-41, 2007.

VIEIRA, Marta; CASTRO, Marinella de. Artesanato associado à tradição cresce em 83,7\% dos municípios de minas. Jornal Estado de Minas. 25 dez. 2016. Seção Economia. Disponível em:

https://www.em.com.br/app/noticia/economia/2016/12/25/internas_economi a,835015/artesanato-associado-a-tradicao-cresce-em-83-7-dos-municipios-demg.shtml. Acesso em: 7 jan. 2020. 
CAROLINA NASCIMENTO PEREIRA é bacharel em Artes Plásticas pela Escola de Belas Artes na Universidade Federal da Bahia. Mestra em Desenho Cultura e Interatividade, pelo Programa de Pós-graduação em Desenho, Cultura e Interatividade, promovido pela Área de Artes Gráficas e Visuais do Departamento de Letras e Artes da Universidade Estadual de Feira de Santana.

E-mail: pereira8carol@gmail.com

(1) http://orcid.org/0000-0002-1025-5221

GLÁUCIA MARIA COSTA TRINCHÃO é professora plena do Departamento de Letras e Artes, Universidade Estadual de Feira de Santana. Licenciada em Desenho e Plástica (EBA/UFBA). Mestra em Arquitetura e Urbanismo (FAU/UFBA). Doutora em Educação (Unisinos). Pós-Doutora em Educação (ULisboa). Professora Plena de Desenho na Universidade Estadual de Feira de Santana (UEFS), da Pós-Graduação Lato Sensu (Especialização em Desenho Registro e Memória Visual) e Stricto Sensu (Mestrado em Desenho, Cultura e Interatividade e do Mestrado em Educação). Lidera o grupo de pesquisa Estudos Interdisciplinares em Desenho (CNPq). Coordena o Programa de Pesquisa Integrada: Estudos Interdisciplinares em Desenho (UEFS).

E-mail: gaulisy@gmail.com

(1) http://orcid.org/0000-0002-0552-1089

Recebido em: 31 de março de 2020

Aprovado em: 20 de maio de 2020

Editora responsável: Dóris Almeida 